\title{
Aulas a Distância na Quarentena: Um Relato de Experiência sobre o Uso de TDICs no Ensino Fundamental Anos Finais
}

\author{
Clarissa Bezerra de Melo Pereira Nunes', Andressa Kroeff Pires ${ }^{1}$
}

${ }^{1}$ Instituto Metrópole Digital (IMD) - Universidade Federal do Rio Grande do Norte (UFRN) - Av. Senador Salgado Filho, 3000, CEP 59.078.970 - Natal - RN - Brasil.

(klanunes, kroeffzinha) dufrn.edu.br

\begin{abstract}
This work reports an experience in distance education with middle school students due to the COVID-19 pandemic. Google tools and a virtual learning environment (VLE) were used as educational resources within a didactic sequence. The teachers experience with the institutional VLE proved to be fundamental for the systematic and uninterrupted execution of the work, with the VLE being used not only as a platform to gather materials and links, but also as a tool for carrying out training activities, which focused on the concepts being learned, in a way to enable teachers to monitor the development of the students during such a unique time.
\end{abstract}

Resumo: Este trabalho relata uma experiência em educação à distância com alunos do Ensino Fundamental anos finais devido à pandemia do COVID-19. Ferramentas do Google e um ambiente virtual de aprendizagem (AVA) foram utilizados como recursos educacionais dentro de uma sequência didática. A experiência do corpo docente com o AVA da instituição mostrou-se fundamental para a execução sistematizada e ininterrupta do trabalho, sendo o AVA utilizado não só como uma plataforma para reunir materiais e links, mas também como uma ferramenta para a realização de atividades formativas, com foco no trabalho de conceitos e aprendizagem, para possibilitar aos docentes acompanhar o desenvolvimento de seus alunos durante tal situação ímpar.

\section{Introdução}

A vida em um mundo hiperconectado, onde a informação é compartilhada tão rapidamente quanto é produzida, oferece desafios a todos os instantes. Resolver transações bancárias comuns têm se tornado tão fácil quanto encomendar a próxima refeição ou encontrar um local a partir do caminhar por ruas virtuais.

Ao passo que a modernidade apresenta celeridade e facilidades de comunicação, também carrega consigo imprevisibilidade e incertezas, como o momento atual onde o mundo sofre e tenta reagir a uma pandemia cujos cuidados básicos tange o cuidado com a higiene e o distanciamento social.

Em meio às incertezas, o setor educacional brasileiro busca formas de reagir frente aos novos desafios. Enquanto algumas escolas suspendem suas aulas, antecipam férias escolares, modificam seus calendários, outras instituições tentam, através da 
tecnologia, reinventar a sala de aula e oportunidades educativas [Antunes 2020; Lupion 2020].

Fora do Brasil, o cenário de pandemia e distanciamento social também é visto como algo desafiador e promotor de oportunidades. Saavedra (2020) apresentou, no fim de Março de 2020, dados informando que, até 28 de Março, a pandemia do COVID-19 estava levando mais de 1.6 bilhões de crianças e adolescentes a estarem sem aulas em mais de 161 países, o que representa quase $80 \%$ dos alunos matriculados, a nível global.

Enquanto a maioria das pessoas está acertadamente preocupada com os impactos imediatos que essa quebra de rotina escolar pode causar às crianças e adolescentes (perdas relacionadas à aprendizagem, evasão e abandono escolar, e crianças deixando de fazer refeições que só faziam na escola), muita criatividade está sendo vista em muitos países, com estratégias capazes de atingir a maior parte das pessoas sendo pensadas e colocadas em prática, levando em consideração a infraestrutura local [Saavedra 2020].

A UNESCO (2020) recomenda o uso racional das tecnologias mais adequadas de acordo com os serviços de energia elétrica e comunicações da área em questão, bem como as capacidades dos alunos e professores. $\mathrm{O}$ uso adequado das ferramentas digitais auxilia na construção de habilidades cognitivas e de aprendizagem, e a criação de testes e exercícios auxiliam a avaliar continuamente como a aprendizagem está ocorrendo. Adicionando a isso, a SBP (2019) prevê que as rotinas do uso saudável da tecnologia devem fazer parte dos projetos pedagógicos, de forma a construir o entendimento do uso em tempo e conteúdo adequado pelas próprias crianças.

Este trabalho objetiva relatar uma experiência em educação à distância, devido à pandemia do COVID-19, com o uso de ambientes virtuais de aprendizagem (AVAs), do Google Drive e Google Meet, com alunos do $6^{\circ}, 7^{\circ}$ e $9^{\circ}$ ano do Ensino Fundamental 2.

\section{Trabalhos relacionados}

Para iniciar a feitura deste artigo, foram feitas buscas no Portal de Publicações da Comissão Especial de Informática na Educação (CEIE), o qual indexa publicações de 7 periódicos nacionais (Revista Brasileira de Informática na Educação, Simpósio Brasileiro de Informática na Educação, Anais do Workshop de Informática na Escola, Anais dos Workshops do Congresso Brasileiro de Informática na Educação, Jornada de Atualização em Informática na Educação, Anais do Workshop de Desafios da Computação Aplicada à Educação, Workshop on Advanced Virtual Environments and Education).

Ao buscar trabalhos, publicados em qualquer ano, que reunissem as palavras-chave "relato de experiência" e "EaD", 04 trabalhos foram encontrados. Já a busca pelos termos "relato de experiência" e "distância" retornou 09 trabalhos, sendo 05 deles descartados por: 1 já ter aparecido na primeira busca, 1 ter sido removido do portal, de tal modo que seu apenas resumo estava acessível, e outros 3 por tratarem de relatos de experiência de vida, sem se relacionar com estudos aplicados. A tabela 01 a seguir organiza as principais informações sobre os trabalhos encontrados, que terão seus objetivos, metodologias e resultados elencados a seguir. 
Tabela 1: Trabalhos encontrados a partir de busca no CEIE.

\begin{tabular}{|l|l|l|l|}
\hline Id & Autores e Título & Ano & $\begin{array}{l}\text { Periódic } \\
\text { o }\end{array}$ \\
\hline E01 & $\begin{array}{l}\text { GONÇALVES, E; VILELA, J; MAIA, M; OLIVEIRA, F; CASTRO, J. } \\
\text { Produça de Videoaulas de Programação em Java Acessíveis no } \\
\text { Contexto de um Projeto de Capacitação Profissional para } \\
\text { Pessoas Surdas. }\end{array}$ & 2015 & SBIE \\
\hline E02 & $\begin{array}{l}\text { LAGO, M; ROSA, G. Pbworks e a Construção de Projetos de } \\
\text { Aprendizagem. }\end{array}$ & 2016 & CBIE \\
\hline E03 & $\begin{array}{l}\text { BONES, A; CAZELLA, S; ROSA DA COSTA, M. Intervenção } \\
\text { Educacional na área da saúde através de objetos de } \\
\text { aprendizagem: um relato de experiência. }\end{array}$ & 2016 & WIE \\
\hline E04 & $\begin{array}{l}\text { KUHN, I; SANTOS JUNIOR, F. D; WIVES, L. K; FERRARI, M. } \\
\text { Relato de uma Experiência Inovadora em um Curso EJA na } \\
\text { Modalidade EAD Semipresencial no ensino fundamental. }\end{array}$ & 2019 & DesafIE \\
\hline E05 & $\begin{array}{l}\text { LEVAY, P; SOARES, F; SANTOS, M. (2017). Inglês sem } \\
\text { distância: Um relato de experiência de oferta de um minicurso de } \\
\text { Inglês a distância para alunos do interior de Pernambuco. }\end{array}$ & 2017 & WIE \\
\hline E06 & $\begin{array}{l}\text { LEITE, R; FIALHO, Vanessa. Relato de experiência com a Khan } \\
\text { Academy em um curso técnico à distância. }\end{array}$ & 2017 & WIE \\
\hline E07 & $\begin{array}{l}\text { DANTAS, E; SOUSA, W; FERNANDES, W; FREIRE, S. A } \\
\text { Trajetória de um Aluno Especial no Curso de Licenciatura em } \\
\text { Computação: Desafios e Superações. }\end{array}$ & 2018 & CBIE \\
\hline E08 Lições Aprendidas no Ensino Fundamental I. & $\begin{array}{l}\text { OLIVEIRA, K; OLIVEIRA, M; ANDRADE, M. Pensamento } \\
\text { Eomputacional, Robótica Educação: um Relato de Experiência }\end{array}$ & WIE \\
\hline
\end{tabular}

Fonte: Elaborado pelas próprias autoras.

O trabalho de Gonçalves et al. (2015) apresenta os resultados obtidos com a produção de videoaulas acessíveis aos deficientes auditivos no contexto de $\mathrm{EaD}$, através de uma pesquisa aplicada com a observação realizadas de forma direta e participante. $O$ objetivo de capacitar profissionais para criar video aulas acessíveis dialoga, ainda que não no mesmo grau, com o trabalho de Bones et al. (2016), que apresenta uma intervenção educacional onde se trabalhou um objeto de aprendizagem por uma equipe multiprofissional atuando de forma interdisciplinar. Eles utilizaram a metodologia da problematização com o foco na capacitação dos alunos e nas competências esperadas em um curso da área da saúde na modalidade Educação a Distância. 
Lago e Rosa (2016) analisam o uso de uma ferramenta (Pbworks) para a construção de projetos voltados à aprendizagem, observando como o engajamento dos alunos é alto e como conseguem aprender melhor a partir de processos colaborativos e cooperativos. A ideia de melhoria também perpassa pelo relato de Kuhn et al. (2019), que trata sobre a estruturação de um curso de Educação de Jovens e Adultos (EJA) semipresencial com uma proposta pedagógica mais flexível, a qual considera o que há de singular em cada educando, quais suas experiências de vida e como isso agrega aos processos de ensino e aprendizagem. Outro trabalho que se volta ao uso de ferramentas com a perspectiva de ganhos pedagógicos é o trabalho de Oliveira et al. (2019) que utilizou a robótica com crianças do quarto ano do Ensino Fundamental anos iniciais para relacionar as ondas sonoras emitidas pelo aparelho ultrassônico do kit LEGO Mindstorms ao ecolocalizador, que é como morcegos, golfinhos e algumas espécies de aves se comunicam na natureza. Segundo as autoras, a pesquisa partiu de uma pergunta norteadora à compreensão de conceitos teóricos e, posteriormente, à resolução de problemas por meio de programação, de modo a promovendo um maior engajamento e autonomia ao possibilitar que os alunos formulassem hipóteses relacionando conhecimentos de ciências e matemática.

Levay et al. (2017) relatam a experiência de um minicurso de Inglês a distância para alunos do interior do estado de Pernambuco, analisando a percepção dos alunos sob uma perspectiva social após a experiência. Os resultados obtidos apontam que o minicurso representou uma primeira oportunidade de contato com a língua inglesa para a maioria dos alunos e estimulou-os a continuar em busca da aquisição da língua, o que pode oferecer-lhes mais e diferentes condições de posicionamento na sociedade. Com a mesma proposta de transformação social, o trabalho de Dantas et al. (2018), conta a trajetória acadêmica de um aluno especial (com déficit cognitivo) no curso de licenciatura em Computação ofertado pela Universidade Estadual do Ceará (UECE) na modalidade de educação a distância. Foram apresentados os passos e as dificuldades enfrentadas durante o curso, principalmente no que tange a falta de preparo das instituições quanto a metodologia e métodos avaliativos, ainda que tenha sido evidenciado acolhimento e apoio para o seu desenvolvimento estudantil.

Leite e Fialho (2017) analisam qualitativamente a plataforma educacional Khan Academy e como alunos do Curso Técnico em Multimeios Didáticos, ofertado à distância, a exploram. O objetivo deste estudo atentou a como instituições de ensino são capazes de explorar ideias e testar hipóteses por intermédio dos instrumentos computacionais mesmo quando em circunstâncias de contingência de recursos materiais e financeiros.

Os trabalhos aqui apresentados relatam soluções de $\mathrm{EaD}$ para contextos diversos que convergem para a educação de adultos à distância, com exceção ao de Oliveira et al. (2019), que foi desenvolvido com alunos do Ensino Fundamental e traz contribuições muito válidas no que tange o planejamento da aula, partindo de uma pergunta para se trabalhar com o conteúdo, seguido de um momento de experimentação e exercício. Nesse sentido, as maiores contribuições encontradas por este levantamento são aquelas voltadas a propostas pedagógicas de como desenvolver os processos de ensino e aprendizagem de forma não-presencial, de maneira a basear e balizar a proposta metodológica relatada nas próximas seções. 


\section{Metodologia}

Para planejar como as aulas a distância seriam realizadas com alunos do $6^{\circ}, 7^{\circ}$ e $9^{\circ}$ ano, foi preciso elencar quais ferramentas foram indicadas e disponibilizadas pela instituição de ensino, e quais as orientações com relação aos formatos das aulas e dos encontros online. Aqui é importante salientar que a escola se apoiou nos Manuais de Orientação disponibilizado pela Sociedade Brasileira de Pediatria [SBP 2016; SBP 2019], onde recomenda que o tempo de uso diário ou a duração total/dia do uso de tecnologia digital seja limitado e proporcional às idades e às etapas do desenvolvimento cerebral-mental-cognitivo-psicossocial das crianças e adolescentes.

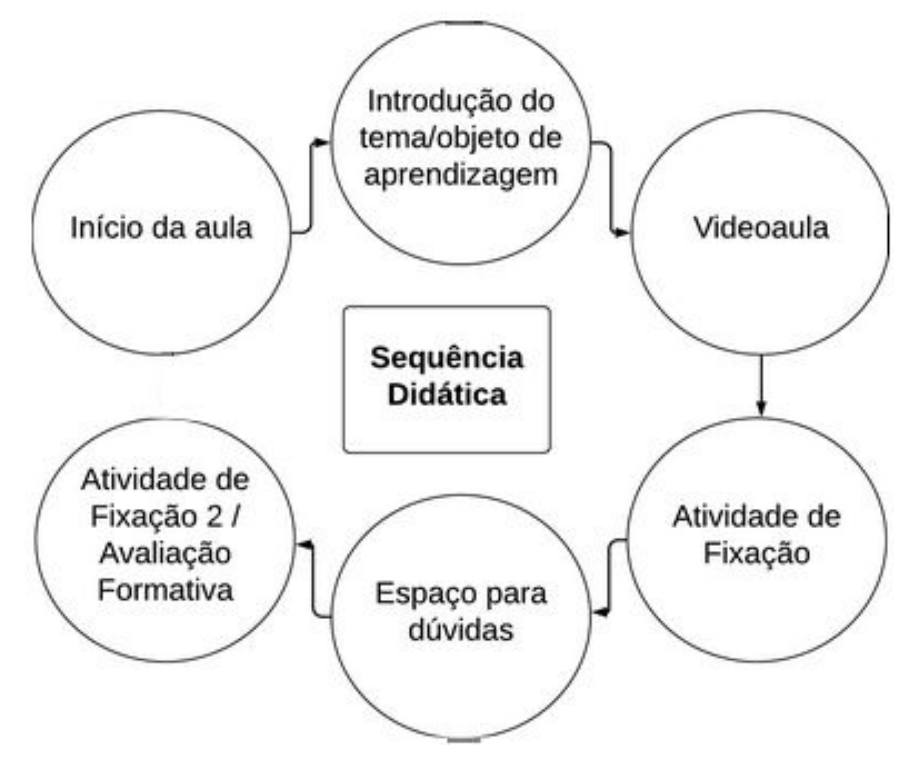

Figura 01: Formato da aula (sequência didática simplificada).

Fonte: Elaborado pelas próprias autoras.

Dessa forma, inicialmente foi realizada uma reunião com o corpo docente, orientadora pedagógica, coordenadoras, psicólogas e profissionais do departamento de Tecnologia Educacional para que a equipe pudesse discutir sobre diferentes formatos de aula, de atividades e diferentes formas de se trabalhar os conteúdos e objetos de aprendizagem. Por fim, chegou-se ao formato de aulas apresentado na Figura 01, para que as aulas ministradas à distância, pudessem ser aproveitadas ao máximo, tanto pela equipe escolar, quanto pelos alunos e suas famílias.

\subsection{A sequência didática.}

As aulas à distância respeitaram a duração das aulas (50 minutos), o horário e as disciplinas dos alunos e dos professores, tal qual nas aulas presenciais. Para o caso de aulas geminadas (duas aulas da mesma disciplina em sequência), coube aos professores 
decidir se utilizariam a sequência em dois momentos (para trabalhar assuntos diferentes), ou se otimizariam a sequência para o período de 100 minutos corridos.

A primeira etapa, de início da aula, com duração sugerida de 5 minutos, objetivou estreitar as relações entre alunos e professores (discussão sobre amenidades, a fim de atenuar sentimentos como ansiedade e estresse), e também permitiu que fosse feita a chamada para se averiguar que alunos estavam ou não comparecendo a cada aula.

A segunda etapa, com duração sugerida de 5 minutos, visou apresentar o tópico que seria trabalhado na aula, ou retomar algo que estava sendo trabalhado: uma forma de nortear e situar os alunos com relação aos objetivos daquele encontro.

A terceira etapa consistiu em indicar aos alunos assistir a uma vídeoaula, gravada previamente, hospedada no Google Drive e disponibilizada no AVA Moodle da turma. Para alunos de $6^{\circ}$ e $7^{\circ}$ ano, os vídeos deveriam durar em torno de 10 minutos por horário de aula, enquanto que para alunos do $9^{\circ}$ ano, os vídeos poderiam ter duração aproximada de 15 minutos, por horário de aula. Esses valores encontram-se em consonância com o preconizado pela Sociedade Brasileira de Pediatria [SBP 2019].

Após o momento instrucional da etapa 3, que poderia ser retomado quantas vezes necessárias por ser um vídeo, a quarta etapa requeriu dos alunos a feitura de atividades de fixação.

O quinto momento foi uma consequência da etapa anterior, uma extensão da mesma ou, ainda, uma antecipação da sexta etapa. A idéia foi de dispor tempo online para os alunos trabalharem suas duvidas com o professor, durante o momento da aula.

A sexta, e última etapa, visou a feitura de mais atividades de fixação, oportunizando também a feitura de atividades de avaliação formativa (que ocorre durante os processos de ensino-aprendizagem) para possibilitar, ao corpo docente, acompanhar o desenvolvimento dos alunos [Borges et al. 2014].

\subsection{Recursos e ferramentas tecnológicos}

Para possibilitar os encontros online de uma forma segura, a Direção da escola comunicou aos pais e funcionários que, respeitando-se os horários das aulas, professores e alunos iriam se encontrar por meio do Google Meet, que é uma ferramenta de videoconferência multiplataforma. A decisão foi motivada por dois motivos: a instituição é parceira do Google Educação, de tal forma que todos os alunos do Ensino Fundamental 2 e Ensino Médio já dispunham de um e-mail institucional; e por questões de segurança, já que no Google Meet é possível autorizar que apenas usuários com determinados e-mails acessem a reunião, o momento online, a sala de aula virtual.

Para hospedar vídeos e materiais diversos, cada profissional, também usando seu e-mail institucional, fez uso de uma conta do Google Drive, em pastas específicas criadas pelos orientadores pedagógicos, de forma a facilitar o acesso a recursos por várias pessoas da equipe, conferindo agilidade para auxiliar na resolução de quaisquer problemas.

Ferramentas online para a feitura de atividades de fixação e avaliação também foram utilizadas, como o Google Formulários, Kahoot e Quizziz. Outras também 
destacaram-se, como o Google Apresentações, Google Documentos e Coggle, como forma de viabilizar trabalhos colaborativos em grupo.

Por fim, mas não menos importante, um ambiente virtual de aprendizagem (AVA) foi utilizado para reunir não só todas as informações necessárias para o momento, como os links para acessar o Google Meet, para acessar os materiais dispostos no Google Drive, mas também para disponibilizar outros materiais, atividades de fixação e avaliação, links para a submissão de tarefas e fóruns de discussão, onde os alunos poderiam postar dúvidas que surgissem após o momento online, de forma assíncrona (isto é, que não ocorrem em tempo real). É importante ressaltar que a instituição adotou o AVA Moodle como ferramenta adicional às aulas presenciais desde 2015, tendo os professores já adotado o uso da ferramenta em suas rotinas diárias, seja para disponibilizar materiais pedagógicos ou realizar atividades avaliativas, para citar alguns usos.

\section{Resultados e Discussão.}

A experiência do corpo docente com o AVA da instituição mostrou-se fundamental no que se referiu à rápida adaptação dos profissionais para a nova situação. Houve a publicação de um decreto estadual em 17 de Março de 2020 à tarde, suspendendo atividades escolares, dentre outras coisas, para não provocar aglomerações. No dia seguinte, 18 de Março de 2020, houve uma reunião para planejamento dos próximos passos e definição da sequência didática, de tal forma a comunidade escolar já foi prontamente informada sobre como as aulas aconteceriam, e os professores já puderam postar conteúdos no AVA, para que os encontros virtuais começassem, sem intercorrências, no dia seguinte, respeitando-se os horários regulares de aula.

Ferramentas suplementares, como o Google Drive, mostraram-se essenciais no sentido de hospedar materiais robustos, como vídeoaulas, para que pudessem ser disponibilizadas pelo AVA. O motivo dos vídeos não serem postados diretamente no ambiente virtual referem-se a questões de armazenamento, para não prejudicar o desempenho do mesmo, uma vez que a previsão de utilização simultânea do AVA poderia provocar problemas técnicos devido à sobrecarga de informação - o que mostrou-se como uma decisão acertada, posto que nos primeiros dias de acesso o ambiente virtual mostrou-se instável por alguns momentos.

O uso do Kahoot, Coggle e Quizziz permitiu a flexibilização da aula no que se refere ao protagonismo dos alunos. Essas ferramentas, juntamente com outras, como o Google Apresentações, permitiram aos estudantes apresentar seus trabalhos e atividades no momento da aula, no próprio Google Meet. Isso dialoga com o que preconiza a SBP (2019) sobre o uso de boas ferramentas para ensino de habilidades e para trabalhar funções executivas pode auxiliar no seu desenvolvimento, desde que sejam respeitadas as recomendações de idade, tempo, horário e conteúdo.

Também existiram dificuldades e desafios. Houve alunos que não puderam estar presentes nos momentos online por várias questões, como problemas técnicos e questões de saúde. Alguns problemas técnicos, como conexões lentas com a internet, ou até mesmo a falta de pacote de dados ou a não existência de câmeras trouxeram desafios para os momentos síncronos, sobretudo no que se denominou como "mapeamento 
visual de engajamento" (quando o professor consegue, visualmente, compreender que alunos estão acompanhando a aula, tão comum nas aulas presenciais). Como alternativa para contornar estes problemas e desafios, foram disponibilizadas videoaulas e as sequências didáticas em todo início de semana, escolhas estas que mostraram-se como acertadas, uma vez que coube a esses alunos buscar as informações posteriormente, para não incorrer prejuízos acadêmicos.

Como uma forma de acompanhar o desenvolvimento dos alunos, houve momentos de discussão e apresentação online, foram utilizadas ferramentas avaliativas como as tarefas e questionários criados no próprio AVA. Também foi possível, para o corpo docente, acessar registros do AVA sobre que alunos estavam ou não acessando os materiais ali disponibilizados. Isso contribuiu para a colaboração entre escola e família no sentido da troca de informações na agenda virtual (adotada pela escola desde 2017) sobre como e o que os alunos estavam ou não estudando, uma vez que muitos pais também estavam trabalhando em casa, sem poder acompanhar seus filhos.

\section{Considerações Finais.}

Com o objetivo de relatar uma experiência com alunos do Ensino Fundamental aos finais de uma escola que optou por dar aulas à distância devido à pandemia do COVID-19, estas pesquisadoras trataram sobre como foi pensada e no que consiste a sequência didática desenvolvida e adotada pelos professores da instituição, com o auxílio de ambientes virtuais de aprendizagem (AVAs), do Google Drive e Google Meet, para citar algumas ferramentas digitais.

A experiência dos professores com a utilização do AVA, adotado em 2015, e com uma agenda online, adotada em 2017, mostraram-se como pontos-chave na transição das aulas físicas para as aulas online, bem como a utilização do Google Meet para oportunizar os encontros entre professores e alunos, de acordo com seus horários de aula. Nunes (2019) chama a atenção para o fato de que é imprescindível munir os educadores de conhecimento não só sobre como utilizar as TDICs, mas também sobre como e porquê utilizá-las.

O AVA, inclusive, foi utilizado não só para reunir materiais e links, mas também para a realização de atividades formativas, com foco no trabalho de conceitos e aprendizagem, como uma forma de possibilitar aos docentes acompanhar o desenvolvimento de seus alunos. Isso alinha-se com o que a SBP (2019), pelos departamentos científicos de Pediatria do Desenvolvimento e Comportamento e Saúde Escolar, entende sobre o uso da tecnologia sendo utilizada de forma adequada e apropriada, como uma ferramenta que pode melhorar a vida diária das crianças e ajudá-las em seu desenvolvimento pessoal e intelectual. É preciso utilizar as TDICs em prol do desenvolvimento de habilidades, da construção do saber e da aprendizagem de uma forma a integrar momentos instrucionistas, interacionistas e construcionistas para que todos os sujeitos envolvidos no processo possam transformar-se e transformá-los [Nunes 2019].

Trabalhos futuros podem tratar sobre como a utilização de videoaulas, como o acesso a materiais e a realização de atividades em um AVA podem contribuir para o desempenho escolar. Também há espaço para a replicação desta sequência didática em 
outros tipos de AVA, como o Google Sala de Aula, que é uma ferramenta gratuita oferecida pelo Google para aqueles que tenham uma conta do Gmail. Essa é uma ideia que, estas pesquisadoras acreditam, possibilita fazer um trabalho similar em escolas que não tenham orçamento ou experiência no uso de ambientes virtuais de aprendizagem.

\section{REFERÊNCIAS}

Antunes, A. (2020) As redes municipais de educação diante da pandemia. Fiocruz. 06/04/2020. Disponível em: $<$ https://portal.fiocruz.br/noticia/redes-municipais-de-educacao-diante-da-pandemia $>$ . Acesso em 07/04/2020.

Bones, A., Cazella, S., Costa, M. R. (2016). Intervenção Educacional na área da saúde através de objetos de aprendizagem: um relato de experiência. Anais do Workshop de Informática na Escola (WIE).

Borges, M. C., Miranda, C. H., Santana, R. C., Bollela, V. R. (2014). Avaliação formativa e feedback como ferramenta de aprendizado na formação de profissionais da saúde. Medicina (Ribeirão Preto. Online), 47(3), pp.324-331.

Dantas, E., Sousa, W., Fernandes, W., Freire, S. (2018). A Trajetória de um Aluno Especial no Curso de Licenciatura em Computação: Desafios e Superações.

Gonçalves, E., Vilela, J., Maia, M., Oliveira, F., Castro, J. (2015). Produção de Videoaulas de Programação em Java Acessíveis no Contexto de um Projeto de Capacitação Profissional para Pessoas Surdas. Simpósio Brasileiro de Informática na Educação (SBIE).

Kuhn, I., Santos Junior, F. D., Wives, L. K., Ferrari, M. (2019). Relato de uma Experiência Inovadora em um Curso EJA na Modalidade EAD Semipresencial no ensino fundamental. In: VIII Workshop de Desafios da Computação aplicada à Educação (DesafIE 2019).

Lago, M., Rosa, G. (2016). Pbworks e a Construção de Projetos de Aprendizagem. 1446. Anais dos Workshops do Congresso Brasileiro de Informática na Educação (CBIE).

Leite, R., Fialho, V. (2017). Relato de experiência com a Khan Academy em um curso técnico à distância. Anais do Workshop de Informática Na Escola (WIE).

Levay, P., Soares, F., Santos, M. (2017). Inglês sem distância: Um relato de experiência de oferta de um minicurso de Inglês a distância para alunos do interior de Pernambuco. Anais do Workshop de Informática Na Escola (WIE).

Lupion, B. (2020). Como a pandemia de coronavírus impacta o ensino no Brasil. UOL Notícias. 05/04/2020. Disponível em: $<$ https://noticias.uol.com.br/ultimas-noticias/deutschewelle/2020/04/05/como-a-pand emia-de-coronavirus-impacta-o-ensino-no-brasil.htm> Acesso em 07/04/2020.

Nunes, C. B. M. P. (2019). Perfil dos professores que usam ferramentas digitais em uma escola da rede privada em Natal/RN. Revista Prometeu, Ano V, n. 1. 
Oliveira, K., Oliveira, M., Andrade, M. (2019). Pensamento Computacional, Robótica e Educação: um Relato de Experiência e Lições Aprendidas no Ensino Fundamental I. Anais do Workshop de Informática Na Escola (WIE).

Saavedra, J. (2020). World Bank. Educational challenges and opportunities of the Coronavirus (COVID-19) pandemic. 30/03/2020. Disponível em $<$ https://blogs.worldbank.org/education/educational-challenges-and-opportunities-co vid-19-pandemic > Acesso em 07/04/2020.

SBP (2016). Departamento Científico de Adolescência da SBP. Manual de Orientação da SBP: Saúde de Crianças e Adolescentes na Era Digital - 2016. Disponível em $<$ https://www.sbp.com.br/fileadmin/user_upload/2016/11/19166d-MOrient-Saude-Cr ian-e-Adolesc.pdf> Acesso em 21 Abr 2020.

SBP (2016). Departamentos Científicos de Pediatria do Desenvolvimento e Comportamento e de Saúde Escolar da SBP. Manual de Orientação da SBP: Uso saudável de telas, tecnologias e mídias nas creches, berçários e escolas - 2019. Disponível

em <https://www.sbp.com.br/fileadmin/user_upload/21511d-MO_-_UsoSaudavel_Telas TecnolMidias_na_SaudeEscolar.pdf> Acesso em 21 Abr 2020.

UNESCO. (2020). COVID-19: 10 Recommendations to plan distance learning solutions. $03 \quad$ Mar $2020 . \quad$ Disponível em $<$ https://en.unesco.org/news/covid-19-10-recommendations-plan-distance-learning-s olutions> Acesso em 21 Abr 2020. 